\title{
Lipid Profile in Relation to Body Mass Index among Medical College Students in Dhaka, Bangladesh.
}

\author{
Md. Sakhawat Hossain ${ }^{* 1}$, Md. Daharul Islam², Asadullahil Galib ${ }^{3}$, \\ Roksana Malek ${ }^{4}$, Khaleda Akter ${ }^{5}$, Maksuda Khanam ${ }^{6}$
}

\begin{abstract}
:
Introduction: In Bangladesh, adolescents have unhygienic eating habits; often eating nutritionally unbalanced and junk \& fast food diet that is low in dietary fibre and high in cholesterol, simple sugars, fats and additive. These types of dietary habit lead to obesity and dyslipidaemia. Obesity is a worldwide health problem and it is associated with dyslipidaemia and other metabolic syndrome. Objectives: To observe the relationship between Body Mass Index (BMI) and lipid profile among medical college students in Bangladesh. Materials \& Methods: This cross sectional observational study was conducted in Department of Medicine, Sir Salimullah Medical College \& Mitford Hospital, Dhaka, among the 100 undergraduate medical students. Detailed history, clinical examination and thorough investigations were done and the findings were recorded on a proforma. Data was processed and analysed with the help of computer program SPSS and Microsoft excel. Results: Maximum subjects (57.0\%) were in the age group 21-23 years. Mean age was $23.42 \pm 4.5$ years. The prevalence of the different abnormal lipid profile including hypercholesterolaemia, low level of HDL, high level of LDL and hypertriglyceridaemia were: $22.0 \%, 31.0 \%, 30.0 \%$ and $28.0 \%$ respectively. Hypercholesterolaemia and hypertriglyceridaemia levels were significantly associated with increasing body mass index. Conclusion: Overweight and obesity is common among the study subjects and those with higher BMI particularly the older ones tend to have abnormal lipid profile. Therefore adequate dietary control, food habit \& life-style modification is needed for prevention of dyslipidemia at early life.
\end{abstract}

Key words: Dyslipidaemia, Body mass index, Obesity

Number of Tables: 06; Number of Figure: 01; Number of References: 20; Number of Correspondences: 05.

*1. Corresponding Author: Dr. Md. Sakhawat Hossain Assistant Professor

Department of Medicine

Sir Salimullah Medical College, Dhaka.

E-mail: sakhawat2311@gmail.com

Mobile no: 01553440606

2. Dr. Md. Daharul Islam

Associate Professor

Department of Medicine

Sir Salimullah Medical College, Dhaka.

3. Dr. Asadullahil Galib

Assistant Professor

Department of Surgery

Khulna Medical College, Khulna.

4. Dr. Roksana Malek

Associate Professor

Department of Biochemistry

Mugda Medical College, Dhaka.

5. Dr. Khaleda Akter

Associate Professor

Department of Gynae \& Obs

Z.H. Sikder Women's Medical College, Dhaka.

6. Dr. Maksuda Khanam

Medical Officer

Department of Radiology \& Imaging

Shahid Sheikh Abu Naser Specialized Hospital, Khulna.

\section{Introduction:}

Obesity is an emerging public health problem throughout the world. In Bangladesh, obesity is emerging as an important health problem particularly in urban areas. The prevalence of obesity is rising to epidemic proportions at an alarming rate in both developed and less developed countries around the world. Recent time shows that overweight and obesity is common among the adolescence and adulthood and those with higher $\mathrm{BMI}^{1}$. In obese there is a positive correlation between BMI and TC and LDL-C levels. In these children, proatherogenic lipid profiles begin early in life $^{2}$. Obesity is associated with hypertension, osteoarthritis, dyslipidemia, indigestion, respiratory and musculoskeletal disorders. In addition, it can cause psychological effects influencing, the quality of life. Central obesity is related to increase in LDL-C/HDL-C ratio, blood pressure and TG levels. Therefore, assessment of BMI should be incorporated into school health programme and those with overweight/obesity subjected to routine lipogram in order to timeously apply preventive as well as therapeutic measures in order to save lives ${ }^{1}$. The associations between overweight and many diseases have been established. Body fat distribution could possibly identify subjects with the highest risk of disturbed lipid profile and hypertension. Disturbed lipid profile has always been associated with cardiovascular diseases. Anthropometric measurements can easily reflect any changes in the lipid concentration in the human body. It was reported that $30 \%$ of the population in the United States in 1995 were overweight. Obesity may increase the risk of many diseases such as diabetes, atherosclerosis, hypertension, hyperlipidemia, 
gall bladder diseases and cardiovascular diseases ${ }^{3}$.

Intra-abdominal fat has been identified as being the most clinically relevant type of fat in humans. Increased level of LDL, high TC, and low levels of HDL are frequently observed in combination with hypertriglyceridemia ${ }^{4}$. Body mass index, waist and hip circumferences were found to be useful anthropometric predictors for cardiovascular risk ${ }^{5}$. A comprehensive nutritional evaluation is also important in these cases. It should involve the subject and his family members. Even adolescents in charge of their own meals should have family members involved in parts of the assessment and counseling ${ }^{6}$. The dietary assessment should include: usual food choices at home, sources of saturated fat and cholesterol, and food choices away from home including those from vending machines, snack, and school lunch ${ }^{7}$. Adolescents with high TC or LDL may have a genetic disorder of lipid metabolism such as familial hypercholesterolemia. Those with homozygous chromosomes forms can experience myocardial infarction or other events in early age. Familial hypercholesterolemia is often diagnosed in adolescence and is characterized by high LDL levels that can be refractory to dietary treatment ${ }^{8}$. Other causes of dyslipidemia include: anabolic steroid use, anorexia nervosa, cigarette smoking, diabetes, glycogen storage diseases, hypothyroidism, liver disease and such medications like corticosteroids, anticonvulsants and certain oral contraceptives. Other causes like overweight and obesity, renal disease, therapeutic diet (ketogenic and high carbohydrate diet) and transplant (bone marrow, heart, kidney, or liver) may also cause dyslipidemia ${ }^{9}$. In adults, high LDL is strongly associated with a higher risk of coronary heart disease (CHD) while high HDL is usually protective. Lowering lipids through dietary or pharmacological therapy has been shown to decrease the incidence of atherosclerotic events. The extent of abnormal lipids and other cardiovascular risk factors in adolescence is related to the severity of atherosclerosis ${ }^{10}$. Encouraging omega-3-fatty acid consumption, increasing dietary fibre intake, fruits, vegetables, cereals, oats, whole grains and legumes are good sources of soluble fibre. Antioxidant food sources carotenoids and vitamins $\mathrm{C}$ and $\mathrm{E}$ - may lower CHD risk. Recommended antioxidant-rich foods such as whole grains, citrus fruits, melons, berries and dark orange/yellow or leafy green vegetables act as supplements ${ }^{11,12}$. Body mass index (BMI) has become the medical standard used to measure over weight and obesity. This is a measure of how appropriate person's weight is for his/her height BMI was calculated as weight in kilograms divided by height in meters squared as indicated by the World Health Organization $^{13,14}$. Association of lipid profiles with obesity and BMI has been reported ${ }^{13,15}$. Therefore, aim of this study is to find out the relationship between Body Mass Index (BMI) and Lipid profile among undergraduate students.

\section{Materials and Methods:}

This descriptive, cross sectional study was conducted in Department of Medicine, Sir Salimullah Medical College
\& Mitford hospital, Dhaka, from 1st July 2018 to 31st December 2018. Total 100 undergraduate medical students were selected according to purposive sampling technique. Subjects with hypothyroidism, obstructive jaundice, on corticosteroid therapy, chronic renal disease, nephritic syndrome, diabetes Mellitus and H/O taking excess alcohol were excluded from study. Detailed history, physical examination and essential investigations like CBC, RBS, serum creatinine and serum lipid profile were done. Subjects are briefed about the objectives of the study, risk and benefits, freedom for participating in the study and confidentiality. Informed consent was obtained accordingly.

Anthropometric: Body mass index (BMI) is a simple index of weight-for-height that is commonly used to classify overweight and obesity in adults. It is defined as a person's weight in kilograms divided by the square of his height in meters $\left(\mathrm{kg} / \mathrm{m}^{2}\right)$, or $\left(\mathrm{BMI}=\mathrm{kg} / \mathrm{m}^{2}\right)$. Height was measured using the height meter and Weight with standardized scale. For Asian population obesity define as BMI between $>25.0$, overweight is $23.1-25.0$ and normal weight is 18.5-23.0.

Lipid profile: The lipid profile of the study sample was analysed according to the according to Third Report of the National Cholesterol Education Program (NCEP) Expert Panel on Detection, Evaluation, and Treatment of High Blood Cholesterol in Adults (Adult Treatment Panel III) classification for identification of dyslipidaemia. Lipid profiles (Total cholesterol, low density lipoprotein, high density lipoprotein, and triglycerides) were measured by direct methods with an automated biochemical analyzer using commercially available diagnostic kit.

\begin{tabular}{lll}
\hline Lipids & \multicolumn{1}{l}{ Value $(\mathrm{mg} / \mathrm{dl})$} & Comments \\
\hline \multirow{3}{*}{ Total Cholesterol } & $<200$ & Desirable \\
\cline { 2 - 3 } & $200-239$ & Borderline high \\
\cline { 2 - 3 } & $\geq 240$ & High \\
\hline \multirow{2}{*}{ HDL Cholesterol } & $<40$ & Low \\
\cline { 2 - 3 } & $\geq 60$ & High \\
\hline \multirow{4}{*}{ LDL Cholesterol } & $<100$ & Optimal \\
\cline { 2 - 3 } & $100-129$ & Near optimal \\
\cline { 2 - 3 } & $130-159$ & Borderline high \\
\cline { 2 - 3 } & $160-189$ & High \\
\hline \multirow{3}{*}{ Triglyceride } & $\geq 190$ & Very high \\
\cline { 2 - 3 } & $150-200$ & Borderline \\
\cline { 2 - 3 } & $201-499$ & High \\
\cline { 2 - 3 } & $\geq 500$ & Very high \\
\hline
\end{tabular}

Dyslipidaemia: The result were considered as dyslipidaemia when lipid profile shows a total cholesterol level of $\geq$ $240 \mathrm{mg} / \mathrm{dl}$; HDL-C level is $<40 \mathrm{mg} / \mathrm{dl}$ in male and $<50 \mathrm{mg} / \mathrm{dl}$ in female; LDL level is $\geq 100 \mathrm{mg} / \mathrm{dl}$; triglyceride level is $\geq$ $200 \mathrm{mg} / \mathrm{dl}$. All the information were recorded in a structured questionnaire. Data was checked and rechecked for omissions, inconsistencies and improbabilities. Data analysis was performed by Statistical Package for Social Science (SPSS), version-22. Data was edited, coded and entered in to the computer. Statistical analyses were done and level of significance was measured by using appropriate 
hypothetical testing. Level of significance ( $p$ value) is set at 0.05 and confidence interval at $95 \%$. Results were presented as text, tables and diagram.

\section{Result \& Observation:}

Total of 100 patients fulfilling inclusion/exclusion criteria were studied. Results and observations are given below: Overall demographic features of 100 subjects are shown in Table I.

Table-I: Demographic characteristics of the patients $(n=100)$.

\begin{tabular}{llll}
\hline Age (years) & \multicolumn{2}{c}{ Frequency } & Total \\
\hline & $\begin{array}{l}\text { Male } \\
(n=83)\end{array}$ & $\begin{array}{l}\text { Female } \\
(n=17)\end{array}$ \\
\hline$<20$ & $9(10.84 \%)$ & 0 & 9 \\
$21-23$ & $48(57.83 \%)$ & $9(52.94 \%)$ & 57 \\
$24-26$ & $19(22.89 \%)$ & $7(41.17 \%)$ & 26 \\
$>26$ & $7(8.43 \%)$ & $1(5.88 \%)$ & 8 \\
\hline Mean \pm SD & \multicolumn{3}{c}{$23.42 \pm 4.5$} \\
\hline
\end{tabular}

In the study, maximum subjects $(57.0 \%)$ were in the age group 21-23 years. Mean age of the participant was $23.42 \pm$ 4.5 years. Out of 100 cases $(83 \%)$ cases were male and $(17 \%)$ were female. Male and female ratio was 4.88:1.

Body mass index demonstrated in Table II. In this study majority of subjects (e.g., 39\%) had BMI 23.1-25.0 (or overweight). Normal weight or BMI $18.5-23.0 \mathrm{~kg} / \mathrm{m} 2$ ) were in $28.0 \%$ subjects and obese were 33 subjects.

Table- II: Evaluation of body mass index $(n=100)$.

\begin{tabular}{lcc}
\hline BMI $\left(\mathrm{kg} / \mathrm{m}^{2}\right)$ & Frequency & Percentage (\%) \\
\hline $18.5-23.0$ & 28 & 28 \\
$23.1-25.0$ & 39 & 39 \\
$>25.0$ & 33 & 33 \\
\hline
\end{tabular}

Table III shows, there were 22 patients with high total cholesterol level $(>240 \mathrm{mg} / \mathrm{dl}), 46$ patients with total cholesterol less than $200 \mathrm{mg} / \mathrm{dl}$ and 32 patients with borderline cholesterol level between 200-239 mg/dl. The highest level of cholesterol was dominant in obese cases. The mean value of total cholesterol level was $242.8 \pm 56.1 \mathrm{mg} / \mathrm{dl}$. The result was significant $(\mathrm{p}=0.032)$.

Table-III: Association of BMI with serum total cholesterol level $(n=100)$.

\begin{tabular}{lccc}
\hline \multirow{2}{*}{ Cholesterol level } & \multicolumn{3}{c}{$\begin{array}{c}\text { Distribution of cases according } \\
\text { to BMI }\left(\mathbf{( k g} / \mathrm{m}^{2}\right)\end{array}$} \\
\hline & $\begin{array}{c}\text { Normal } \\
\text { weight }\end{array}$ & $\begin{array}{c}\text { Over } \\
\text { weight }\end{array}$ & Obese \\
\hline$<200 \mathrm{mg} / \mathrm{dl}$ (desired) & 20 & 25 & 1 \\
$201-239 \mathrm{mg} / \mathrm{dl}$ (borderline) & 8 & 11 & 13 \\
$>240 \mathrm{mg} / \mathrm{dl}$ (high) & 0 & 3 & 19 \\
\hline \multirow{2}{*}{ Mean $\pm \mathrm{SD}(\mathrm{mg} / \mathrm{dl})$} & $156.2 \pm$ & $192.7 \pm$ & $242.8 \pm$ \\
& 34.8 & 57.2 & 56.1 \\
\hline
\end{tabular}

The table IV shows the HDL cholesterol limit. The mean HDL cholesterol level was $57.1 \pm 7.2 \mathrm{mg} / \mathrm{dl}$ in normal subjects, $48.9 \pm 5.8 \mathrm{mg} / \mathrm{dl}$ in overweight and $46.1 \pm 5.2 \mathrm{mg} / \mathrm{dl}$ in obese. The difference was statistically non-significant.
Table-IV: Association of BMI with HDL cholesterol $(\mathrm{n}=100)$.

\begin{tabular}{lccc}
\hline \multirow{2}{*}{ HDL cholesterol } & \multicolumn{3}{c}{$\begin{array}{c}\text { Distribution of cases according } \\
\text { to BMI }\left(\mathbf{k g} / \mathrm{m}^{2}\right)\end{array}$} \\
\hline & $\begin{array}{c}\text { Normal } \\
\text { weight }\end{array}$ & $\begin{array}{c}\text { Over } \\
\text { weight }\end{array}$ & Obese \\
\hline$<40 \mathrm{mg} / \mathrm{dl}$ (low) & 5 & 7 & 19 \\
$41-59 \mathrm{mg} / \mathrm{dl}($ borderline) & 13 & 21 & 10 \\
$>60 \mathrm{mg} / \mathrm{dl}(\mathrm{high})$ & 10 & 11 & 4 \\
\hline Mean $\pm \mathrm{SD}(\mathrm{mg} / \mathrm{dl})$ & $57.1 \pm 7.2$ & $48.9 \pm 5.8$ & $46.1 \pm 5.2$ \\
\hline
\end{tabular}

In this study there were 2 patients with LDL cholesterol level more than $190 \mathrm{mg} / \mathrm{dl}$ (very high level), 5 patients with LDL cholesterol level between 160-189 mg/dl (high level), 23 patients with LDL cholesterol level between 130-159 $\mathrm{mg} / \mathrm{dl}, 39$ patients with LDL cholesterol level between $100-129 \mathrm{mg} / \mathrm{dl}$, and 31 patients with LDL cholesterol level less than $100 \mathrm{mg} / \mathrm{dl}$ (optimal level). The mean LDL cholesterol level was $89.4 \pm 15.8$, in normal subject, $104.6 \pm 20.1$ in overweight and $105.9 \pm 19.9$ in obese. The result was statistically non- significant (Table V).

Table-V: Association of BMI with serum LDL cholesterol $(n=100)$.

\begin{tabular}{lccc}
\hline LDL cholesterol level & \multicolumn{3}{c}{$\begin{array}{c}\text { Distribution of cases according } \\
\text { to BMI }\left(\mathbf{k g} / \mathrm{m}^{2}\right)\end{array}$} \\
\hline & $\begin{array}{c}\text { Normal } \\
\text { weight }\end{array}$ & $\begin{array}{c}\text { Over } \\
\text { weight }\end{array}$ & Obese \\
\hline$<100 \mathrm{mg} / \mathrm{dl}$ (optimal) & 18 & 7 & 6 \\
$101-129 \mathrm{mg} / \mathrm{dl}$ (beyond optimal) & 3 & 17 & 19 \\
$130-159 \mathrm{mg} / \mathrm{dl}$ (nearly high) & 4 & 12 & 7 \\
$160-189 \mathrm{mg} / \mathrm{dl}$ (high) & 2 & 3 & 0 \\
$>190 \mathrm{mg} / \mathrm{dl}$ (very high) & 1 & 0 & 1 \\
\hline \multirow{2}{*}{ Mean $\pm \mathrm{SD}$ (mg/dl) } & $89.4 \pm$ & $104.6 \pm$ & $105.9 \pm$ \\
& 15.8 & 20.1 & 19.9 \\
\hline
\end{tabular}

Table-VI: Association of BMI with serum triglyceride (TG) level $(n=100)$

\begin{tabular}{|c|c|c|c|}
\hline \multirow[t]{2}{*}{ TG level } & \multicolumn{3}{|c|}{$\begin{array}{c}\text { Distribution of cases according } \\
\text { to BMI }\left(\left(\mathrm{kg} / \mathrm{m}^{2}\right)\right.\end{array}$} \\
\hline & $\begin{array}{l}\text { Normal } \\
\text { weight }\end{array}$ & $\begin{array}{c}\text { Over } \\
\text { weight }\end{array}$ & Obese \\
\hline$<150 \mathrm{mg} / \mathrm{dl}$ & 24 & 22 & 9 \\
\hline $151-199 \mathrm{mg} / \mathrm{dl}$ (borderline) & 3 & 8 & 6 \\
\hline 200-499 mg/dl (high) & 1 & 5 & 16 \\
\hline > 500 mg/dl (very high) & 0 & 4 & 2 \\
\hline Mean \pm SD $(\mathrm{mg} / \mathrm{dl})$ & $\begin{array}{c}96.7 \pm \\
14.8\end{array}$ & $\begin{array}{c}112.7 \pm \\
17.2\end{array}$ & $\begin{array}{c}187.5 \pm \\
18.1\end{array}$ \\
\hline
\end{tabular}

Table VI shows majority of cases of normal weight \& overweight participant (e.g., 46.0\%) have normal range of triglyceride. But in obese cases, 16 participants have high level of TG. The high level of triglyceride was dominant in obese respondents. The mean triglycerides level was $96.7 \pm$ 14.8 in normal subject, $112.7 \pm 17.2$ in overweight and $187.5 \pm 18.1$ in obese. The result was statistically significant $(\mathrm{p}=0.016)$. 


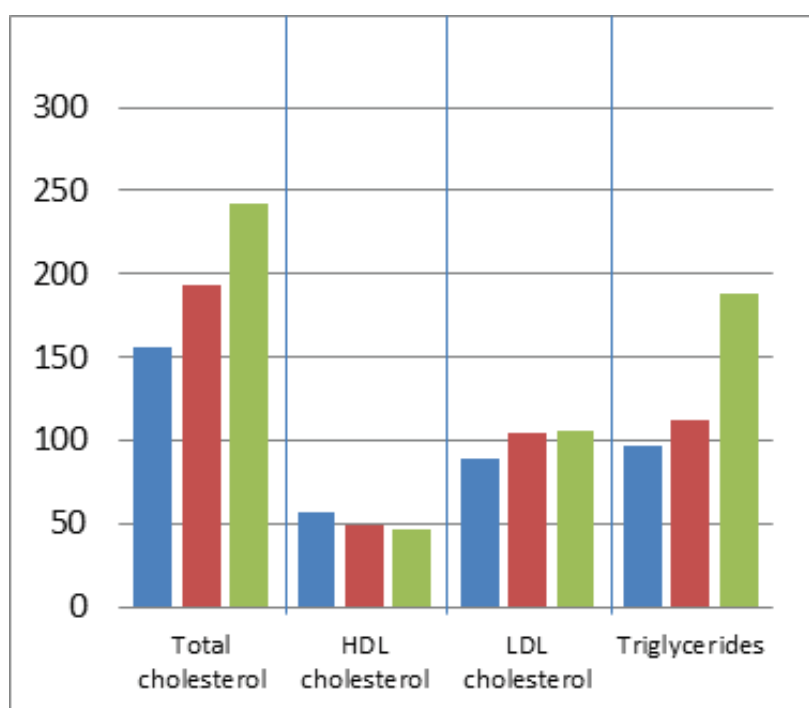

Normal weight $\quad$ Overweight $\quad$ Obese

Figure- 1: Summary of dyslipidemia in different group of subjects $(\mathrm{n}=100)$.

In this study significant association was found in total cholesterol level \& triglyceride level with obesity. HDL cholesterol and LDL cholesterol was non-significant. Among the total 28 cases of normal weight subject, no cases detected cholesterol abnormality, 3(10.71\%) were high LDL, 15(53.57\%) were low HDL and $1(3.57 \%)$ were high TG level. (Blue column) Among the 39 cases of overweight subject, 3(7.69\%) found high cholesterol, $17(43.58 \%)$ were high LDL, 7(17.94\%) recorded low HDL and $9(23.07 \%)$ cases were raised TG level. (Red column) Among the total 33 cases of obese cases, 19(57.57\%) were high serum cholesterol, 1(3.03\%) detected as high LDL, $19(57.57 \%)$ low HDL and $18(54.54 \%)$ of cases found high TG (Olive green column).

\section{Discussion:}

There has been rising burden of childhood \& adolescent obesity in most developing countries despite high prevalence of under nutrition. Obesity is associated with abnormal lipid levels that could result in a variety of metabolic and cardiovascular complications. Therefore present study was conducted to determine the association of body mass index (BMI) and lipid profile in undergraduate medical student. In this study, maximum subjects $(57.0 \%)$ were in the age group 21-23 years. Mean age of the participant was $23.42 \pm 4.5$ years. Out of 100 cases $(83 \%)$ cases were male and $(17 \%)$ were female. On evaluation of BMI, $33 \%$ and $39.0 \%$ were obese and overweight respectively. The prevalence of the different abnormal lipid profile including hypercholesterolaemia, low level of high density lipoprotein cholesterol (HDL-C), high level of low density lipoprotein cholesterol (LDL-C) and hypertriglyceridaemia were: $22.0 \%, 31.0 \%, 30.0 \%$ and $28.0 \%$ respectively. Findings consistent with result of previous study. Eke et al reported that prevalence of the different abnormal lipid profile including hypertriglyceridaemia, low level of high density lipoprotein cholesterol (HDL-C), hypercholesterolaemia, and high level of low density lipoprotein cholesterol (LDL-C) were: $13.4 \%, 9.4 \%, 6.3 \%$ and $5.4 \%$ respectively. Hypercholesterolaemia, hypertriglyceridaemia and increased LDL-C levels were significantly associated with increasing body mass index in the study subjects ${ }^{1}$. Rising prevalence of obesity and overweight has been reported globally, and obesity is now a leading nutritional disorder requiring urgent attention. Obesity earlier considered a problem of high income countries is now on the rise in most low and middle income countries particularly in urban settings ${ }^{1}$. In this study maximum participant were urban population and middle to high class of economic background. The current study has demonstrated that there is a positive correlation between high body mass index (as evident in overweight and obesity) with abnormal lipid profile including hypercholesterolaemia, hypertriglyceridaemia and a high LDL - $\mathrm{C}$ among subjects. In this study significant difference in serum total cholesterol \& triglycerides was observed with high BMI, but LDL-C and HDL-C was non-significant. Findings of our study are consistent with the previous studies ${ }^{1,13}$. Begum et al noted that no significant difference in serum total cholesterol $(\mathrm{P}=0.37)$, LDL-C $(\mathrm{P}=0.53)$ triglycerides $(\mathrm{P}=0.06)$ and HDL-C, $(\mathrm{P}=0.54)$ in three $\mathrm{BMI}$ groups ${ }^{13}$. Eke et al reported that prevalence of the different abnormal lipid levels including hypertriglyceridaemia $13.4 \%$ (47), low HDL-C 9.4\% (23), hypercholesterolaemia $6.3 \%$ (22), and increased LDL-C 5.4\% (19) respectively. Similarly, subjects that were overweight and obese had high mean values for TC, and triglycerides $(p=0.000)$ respectively and lower mean values for HDL $-C(p=0.351)$ compared to normal and underweight subjects ${ }^{1}$. Being overweight or obese can lead to adverse metabolic effects on, cholesterol and triglycerides. Free fatty acids (FFA) are released in abundance from adipose tissue mass. As a consequence, FFA increases the liver production of TG and secretion of VLDL. Hypertriglyceridaemia and VLDL reduce HDL cholestero $^{16}$. Circulating FFA, may contribute to the induction of hypertension16. Obesity in older children is a known predictor of adult obesity and longitudinal studies in adult populations point to a strong association with cardiovascular disease risk ${ }^{17}$. The burden of these likely cardiovascular diseases and insulin resistance syndrome including type 2 diabetes mellitus (DM) have been reported to have poor outcomes in developing countries of sub-Saharan Africa owing to limited economic resources, high prevalence of infectious diseases as well as poor infrastructural facilities to cope with the complications ${ }^{18}$. These findings can be explained by the results of certain studies that showed that hyperinsulinemia and insulin resistance are strongly correlated with obesity. It has been estimated that risk of myocardial infarction is $35 \%$ to $55 \%$ less in adults and normal weight as compared to obese adults ${ }^{19}$. However, the influence of obesity on cardiovascular risk begins before adulthood and overweight during adolescence is associated with an increased risk of coronary heart disease 
in male and female subjects ${ }^{20}$. As $>50 \%$ students of our total study population are overweight $\&$ obese, so number of at-risk individuals is much higher. Therefore, strategies designed to limit cardiovascular risk should address weight reduction during childhood and adolescence.

\section{Conclusion:}

In this study overweight and obesity is common among the undergraduate medical student. Subjects with high BMI tend to have abnormal lipid profile. It was evident that high percentage prevalence of overweight, obesity is the major driving forces in the development of diabetes mellitus, coronary heart disease and metabolic syndrome. We concluded from this study that obesity in significant number of young medical student population. This prevalence may be due to lack of awareness, sedentary lifestyle and unhealthy diet, so health education and more preventive measures should decrease the prevalence of obesity and cardiac risks in our adolescent population by modifying their lifestyle. From our study we have drawn the following suggestions, to decrease the obesity, initially identifying students who are gaining weight, overweight or obese. First step in preventing and treating overweight by interventions, "We recommend to governments to create environments that allow for lifestyle changes. This will require a coordinated approach across all sectors including health, education, sports and agriculture, but it is the only way we can curb the burden of type 2 diabetes and cardiovascular disease."

Conflict of Interest: None.

Acknowledgement:

We are thankful to study subjects for their active, sincere and voluntary participation.

\section{References:}

1. Eke CB. Association of Body Mass Index and Serum Lipid Profile among Adolescents in Enugu, Nigeria. Ann Med Health Sci Res. 2018; 8:404-410.

2. Arjona-Villicaña R, Herrera-Sánchez L, Sumárraga-Ugalde C, Alcocer-Gamboa M. Relationship between body mass index and lipid profile in obese Mexican children and adolescents: A retrospective analysis. Páginas. 2014; 88-94.

3. Troiano RP, Flegal KM, Kuczmarski RJ. Overweight prevalence and trends for children and adolescents. Arch. Pediatr. Adolesc. Med. 1995; 149: 1085-1091.

https://doi.org/10.1001/archpedi.1995.02170230039005

PMid:7550810

4. Lemos-Santos MGF, Valente JG, Gonçalves-Silva RMV, Sichieri R. Waist circumference and waist-to-hip ratio as predictors of serum concentration of lipids in Brazilian men. Nutrition. 2004; 20 (10): 857-862.

https://doi.org/10.1016/j.nut.2004.06.005

PMid:15474872

5. Rexrode KM, Manson JE, Hennekens CH. Obesity and cardiovascular disease. Curr. Opin. Cardiol. 1996; 11: 490-495.

https://doi.org/10.1097/00001573-199609000-00007

PMid:8889375

6. Krauss RM, Eckel RH, Howard B, Appel LJ. AHA Dietary gui-delines: Revision 2000: A statement for healthcare professionals from the Nutrition Committee of the American Heart Association. Circula-tion. 2000; 102 (18): 2284-2299.

https://doi.org/10.1161/01.CIR.102.18.2284

PMid: 11056107

7. Elster AB, Kuznets NJ. Guidelines for adolescent preventive services (GAPS): recommendations and rationale. Chicago, IL: American Medical Association. 1994.

8. Stang J, Story M. Guidelines for Adolescent Nutrition Services. http:// www.epi.umn.edu/let/pubs/adol_book.shtm. 2005.

9. Lichtenstein A. Atheroesclerosis. In: Ziegler EE, Filer LJ (eds). Present Knowledge in Nutrition. Washington DC: ILSI Press; 1996: 430-437.

10. Adams L. Hyperlipidemia. Minneapolis, MN center for leadership, Education and training in maternal and child nutrition, Division of epi-demiology and community health, school of public health, university of Minnesota. 2005; 10 : 109-123.

11. Jacobson MS. Heart healthy diets for all children: no longer controver-sial. J. Pediatr .1998; 133 (1): 1-2.

https://doi.org/10.1016/S0022-3476(98)70167-2

12. Executive Summary of The Third Report of The National Cholesterol Education Program (NCEP) Expert Panel on Detection, Evaluation, and Treatment of High Blood Cholesterol in Adults (Adult Treatment 13- Panel III). JAMA. 2001; 285 (19): 2486-2497.

https://doi.org/10.1001/jama.285.19.2486

PMid:11368702

13. Begum G, Jabeen A, Kumar C, Rahaman A. Comparative Study of Lipid Profile with Body Mass Index in young Healthy Medical Students. International Journal of Biotechnology and Biochemistry ISSN 0973-2691. 2018; 14(1):19-25.

14. World Health Organization. Report of a WHO Expert Committee. Physical status: the use and interpretation of anthropometry. Geneva 1995 (Technical Report Series No. 854). 15. Sanlier N, Yabanci N. Relationship between Body Mass Index, Lipids and Homocysteine levels in university students. J Pak Med Assoc. 2007; 57(10): 491-494.

16. Donahue RP, Orchard TJ, Kuller LH, Drash AL. Lipids and lipoproteins in young adult population. Am J Epidemiol. $1985 ; 240: 458-67$.

https://doi.org/10.1093/oxfordjournals.aje.a114127

PMid:4025295 
17. Chu NF. Prevalence and trends of obesity among school children in Taiwan. The Taipei children Heart study. Int. J of Obesity. 2001; 25:170-176.

https://doi.org/10.1038/sj.ijo.0801486

PMid:11410816

18. Eke CB, Ubesie AC, Ibe BC. Challenges of childhood obesity in a developing economy: a review. Niger J Paed. 2015; 42:169-179.

https://doi.org/10.4314/njp.v42i3.1
19. Manson JE, Tosteson H, Ridker PM, Satterfield S, Hebert P, O'Connor GT, et al. The primary prevention of myocardial infarction. N Engl J Med. 1992; 326:1406-16. https://doi.org/10.1056/NEJM199205213262107

PMid:1533273

20. DiPietro L, Mossberg HO, Stunkard AJ. A 40 year history of overweight children in Stockholm: life-time overweight, morbidity, and mortality. Int J Obes. 1994; 18 : 585-90. 